\title{
Regeneration and Genetic Fidelity Analysis of Chlorophytum borivilianum Using Flower Stalk as Explant Source
}

\author{
Nishant Kaushal, Anshu Alok, Monika Kajal, Kashmir Singh* \\ Department of Biotechnology, Panjab University, Chandigarh, India \\ Email: *kashmirbio@pu.ac.in, ${ }^{\star}$ kashmir123@gmail.com
}

How to cite this paper: Kaushal, N., Alok, A., Kajal, M. and Singh, K. (2021) Regeneration and Genetic Fidelity Analysis of Chlorophytum borivilianum Using Flower Stalk as Explant Source. Advances in Bioscience and Biotechnology, 12, 95-107. https://doi.org/10.4236/abb.2021.124007

Received: March 5, 2021

Accepted: April 13, 2021

Published: April 16, 2021

Copyright $\odot 2021$ by author(s) and Scientific Research Publishing Inc. This work is licensed under the Creative Commons Attribution International License (CC BY 4.0).

http://creativecommons.org/licenses/by/4.0/

\section{(c) (i) Open Access}

\begin{abstract}
Chlorophytum borivilianum is a critically endangered plant well known for its medicinal properties for diabetes mellitus, diarrhea, arthritis, sterility, and erectile dysfunction, etc. Due to low viability and long dormancy of seeds, in vitro regeneration is required for large scale cultivation of this plant. In the present study, direct plant regeneration was optimized using flower stalk as explant. Nodal segments of flower stalk were sterilized and kept for direct regeneration on different combinations of BAP and KIN supplemented media. The highest, $15.27 \pm 1.14$ number of shoots were produced on medium containing BAP (2 $\mathrm{mg} / \mathrm{L}$ ) per nodal segment. The multiple shoot clumps regenerated from flower stalk were separated carefully and kept on rooting media. A maximum of 16.87 \pm 1.53 roots per plant was observed in MS media having $0.5 \mathrm{mg} / \mathrm{L}$ of NAA. The rooted plantlets were shifted into the pot containing soilrite for hardening and acclimatization. The genetic stability of hardened plants was confirmed by start codon targeted, and inter simple sequence repeats molecular markers. All the 18 randomly selected plantlets showed similar genetic homogeneity to the mother plant. It is the first report on in vitro regeneration along with the genetic fidelity analysis of the regenerated plantlets from flower Stalk of $C$. borivilianum. As the standardized method of regeneration and mass multiplication is quite efficient and genetically stable, the protocol will be useful for the large-scale production of $C$. borivilianum to meet the market demand.
\end{abstract}

\section{Keywords}

Chlorophytum borivilianum, In Vitro Regeneration, SCoT, ISSR, Genetic Fidelity

\section{Introduction}

Chlorophytum borivilianum is one of the most valuable medicinal plants of $L i$ - 
liaceae family. Pharmaceutically, it is a very important plant because of its tuberous roots which contains steroidal saponins, alkaloids, steroids, flavonoids, triterpenoids, tannins, and phenolic acids [1] [2]. The medicinal properties of this plant are well known for curing weaknesses, physical illnesses, diabetes mellitus, diarrhea, dysuria, arthritis, sterility, and erectile dysfunction [2] [3]. Dried roots are most commonly used in traditional medicine due to their aphrodisiac and natural tonic properties [4]. Traditionally, it is grown using seeds and tubers. However, vegetative propagation via traditional methods is not sufficient for large scale cultivation [5]. The long dormancy period of $C$. borivilianum seeds, poor seed germination, and low seed viability (11\% - 24\%) limits its natural regeneration methods [6]. Due to these is limitations, in vitro culture based methods are in demand and have been successfully used for micropropagation of different species of Chlorophytum [7] [8]. Tissue culture which includes callus induction, micro-propagation and in vitro tuberization has been reported in different species of Chlorophytum such as C. comosum [9], C. borivilianum [10], C. amanienese [11] and C. arundianceum [8]. In vitro micropropagation depends on the type of explants and growth regulators used in the medium. The clonal propagation of C. borivilianum through multiple shoot induction has been reported using shoot buds, stem discs and, from callus and hypocotyls of geminated seedling using 6-benzylaminopurine (BAP), Kinetin (KIN) and Thidiazuron. As per the previous reports, BAP and $\mathrm{KIN}(0.5$ to $15 \mathrm{mg} / \mathrm{L})$ individually and in combinations with auxins (2,4-D, IAA and IBA) are efficient in shoot induction, proliferation and multiplication. [6] [7] [12] [13] [14] [15]. But the major concern for in vitro regenerated plants is the incidence of somaclonal variations in the form of DNA polymorphism, chromosomal aberrations and sequence changes as the culture techniques, composition of nutrient media, amount and, combinations of growth hormones and growth conditions can cause somaclonal variations in micro propagated plants [16].

Differentiated plant organs (leaves, stems and roots) have the tendency to produce more variations than explants like axillary shoot buds or inflorescences having meristematic tissue [17]. Also, young tissues are less prone to genetic variations as compare to the older tissue [18]. Studies suggest that direct regeneration of plantlets from the explants like apical shoot buds and inflorescence is least prone to genetic modifications [19]. However, a little possibility of occurrence of somaclonal variations still exists as genetic variations do occur in undifferentiated cells, isolated protoplasts, calli, tissues and morphological traits of in vitro raised plants [16] [20] [21]. Genomic fingerprinting can differentiate between individuals, species and populations and is useful for the detection of the homogeneity of the regenerated plants. Therefore, genome based approaches, which include sequence based and direct polymorphism methods, have been developed for the authentication of medicinal plants [22]. The DNA based markers such as SCoT (start codon targeted) and ISSR (inter simple sequence repeats) have been successfully utilized to investigate genetic stability or variability in the tissue culture raised plants in several plant species [14] [23] [24] 
[25].

Micropropagation in $C$. borivilianum has been established using young shoot buds [12] [26], seeds [6], stem discs [27], immature floral buds [15], apical meristems in C.comosum [9] and leaf from in vitro grown plant from C. borivilianum seed [28] as an explants. However, disadvantages like frequent bacterial contamination with stem discs due to their direct contact with soil and poor viability of seeds [10] have been seen.

Present study was designed in accordance to the recent studies of in vitro regeneration and genetic fidelity analysis in different medicinal plants [29] [30] [31]. In our study, we have used flower stalk (nodal segment) as an explant for plant regeneration and multiple shoot induction. The genetic fidelity of regenerated plantlets was then checked using SCoT and ISSR markers. The main idea behind using nodal segments was the presence of active meristems which provide the best platform for multiple shoot induction and regeneration. Moreover, direct regeneration methods would help in maintaining genetic homozygosity. The objective of the study was achieved by healthy flower stalk selection, in vitro regeneration of the nodal segments to produce plantlets, greenhouse acclimatization and genetic fidelity analysis of the hardened plants using molecular markers.

\section{Materials and Methods}

\subsection{Surface Sterilization and Explant Preparation}

Plants of C. borivilianum were maintained in culture room of department of biotechnology at Panjab University, Chandigarh. Approximately, 2 - 3 Flower stalks each having 4 - 5 internodes were taken, washed thoroughly under running tap water. The surface sterilization was done with $0.1 \%$ mercuric chloride for 2 - 3 min and them washed with autoclaved distilled water for 4 - 5 times. Nodal segments of flower stalk were then cut into $3-4 \mathrm{~cm}$ pieces and kept on shooting media.

\subsection{Media Preparation and Culture Conditions}

Murashige and Skoog's (MS) basal medium [32] having calcium chloride, vitamins, sucrose and agar (Himedia, India) was used for in vitro experiments. MS media was dissolved in deionized water, growth regulators [Benzyl aminopurine (BAP) and Kinetin (KIN)] were added, and $\mathrm{pH}$ was adjusted to 5.8. All cultures were kept at $25^{\circ} \mathrm{C} \pm 2^{\circ} \mathrm{C}$ under $16 \mathrm{~h}$ light and $8 \mathrm{~h}$ dark photoperiod having light intensity of 3000 lux.

\subsection{Media Optimization for Direct Regeneration Using Flower Stalk}

Direct regeneration of multiple shoots from nodal segment of flower stalk was optimized using different cytokinin (BAP/KIN) concentrations varied from 0 - 4 mg/L (Table 1). 5 - 6 Sterilized nodal explants were inoculated per Petri dish 
having different hormone combinations. The cultures were kept in light as mentioned above and after every 14 - 15 days the fresh medium was used for the subculturing of explants. The number of regenerated shoots was counted after 6 - 8 weeks of initiation of cultures.

\subsection{Root Media Optimization}

Multiple shoots clumps originated from somatic embryos and nodal segment were separated for rooting. The individual shoots were kept onto different media. MS medium supplemented with root initiation medium (RIM) having different concentrations of NAA $(0.25,0.5$ and $1 \mathrm{mg} / \mathrm{L})$ and IAA $(0.25,0.5$ and $1 \mathrm{mg} / \mathrm{L}$ ) were used for root induction. MS full strength and MS half strength media were used as controls to check the effect of growth regulator free media on root induction. The root number and length were observed after 6-8 weeks of initiation of cultures (Table 2).

\subsection{Hardening and Acclimation}

Each well rooted plantlet was taken out from a bottle or a test tube and washed carefully with tap water to remove agar from the roots. Plants were transferred to pots containing soilrite and covered with perforated polythene bags. These poly bag covered pots were shifted to Percival growth chamber (Percival, USA) for 2 weeks under controlled conditions. After 2 weeks poly bags were removed and again kept for one week in growth chamber. Finally, after one-week plants were exposed to the external environment.

\subsection{Genomic DNA Isolation and Polymerase Chain Reaction (PCR)}

Total genomic DNA was isolated from 40 - 45 hardened plants and mother plants using DNeasy Plant Mini Kit (QIAGEN, Germany). The purity of DNA was checked on $0.8 \%$ agarose gel. The DNA was quantified using spectrophotometer (Bio-Rad, U.S.A.). Each DNA sample was diluted with sterile distilled water to make the concentration $100 \mathrm{ng} / \mu \mathrm{l}$. A total of $8 \mathrm{SCoT}$ and 4 ISSR primers were selected from previous genetic fidelity studies (Table 3) [32]. PCR was performed using Dream Taq polymerase enzyme (Thermo Fisher, U.S.A.) and $100 \mathrm{ng}$ DNA as template. Each PCR reaction contains, $2.5 \mu \mathrm{l} 10 \mathrm{X}$ buffer, $1 \mu \mathrm{l} 10$ $\mathrm{mM}$ dNTP, 10 pmol primer $1 \mathrm{U}$ Dream taq enzyme, and nuclease free water in total volume up to $25 \mu \mathrm{l}$. The PCR reaction was carried out in a thermal cycler (Bio-Rad, U.S.A.). The amplification cycles conditions were as follow: initial denaturation: $94^{\circ} \mathrm{C}$ for 3 minutes; 35 cycles of denaturation: $94^{\circ} \mathrm{C}$ for 45 seconds; annealing: $42^{\circ} \mathrm{C}-45^{\circ} \mathrm{C}$ for 1 minute; extension at $72^{\circ} \mathrm{C}$ for 90 seconds and final extension at $72^{\circ} \mathrm{C}$ for 10 minutes for total 35 number of cycles. PCR products were then separated onto $1 \%$ agarose gel using Good view staining dye (Br Biochem, India) in Tris acetic acid EDTA (TAE) buffer. The bands were visualized using gel documentation system (Bio-Rad, U.S.A.). Banding patterns were analyzed for polymorphism. 
Table 1. Effect of Cytokinins (BAP and KIN) on shoot regeneration using flower stalk of C. borivilianum.

\begin{tabular}{cccc}
\hline MEDIA & BAP $(\mathrm{mg} / \mathrm{L})$ & Kinetin $(\mathrm{mg} / \mathrm{L})$ & No. of shoot per nodal explant \\
\hline Control (MS) & - & - & $0.87 \pm 0.12^{\mathrm{g}}$ \\
SIM1 & 1 & - & $7.40 \pm 1.04^{\mathrm{ef}}$ \\
SIM2 & 2 & - & $15.27 \pm 1.14^{\mathrm{a}}$ \\
SIM3 & 3 & - & $11.13 \pm 0.64^{\mathrm{c}}$ \\
SIM4 & 4 & 0.5 & $9.13 \pm 1.21^{\mathrm{d}}$ \\
SIM5 & - & 1 & $6.20 \pm 1.00^{\mathrm{f}}$ \\
SIM6 & - & 2 & $12.60 \pm 1.20^{\mathrm{b}}$ \\
SIM7 & - & 3 & $9.13 \pm 0.31^{\mathrm{d}}$ \\
SIM8 & - & $8.60 \pm 0.72^{\mathrm{de}}$ \\
\hline
\end{tabular}

$\mathrm{N}=3$ with each replicate consists of 5 explants per treatment. Value in column represents mean \pm Standard deviation. Mean with same letter with in column are not significantly different $(\mathrm{P} \leq 0.05) .{ }^{*} \mathrm{~N}=3$ (Each replicate of regeneration studies consists minimum of 5 cultures).

Table 2. Effect of media and auxins (NAA/IAA) on root induction and proliferation of regenerated shoots of C. borivilianum.

\begin{tabular}{ccccc}
\hline MEDIA & NAA $(\mathrm{mg} / \mathrm{L})$ & IAA $(\mathrm{mg} / \mathrm{L})$ & Root number $(\mathrm{mean} \pm \mathrm{SD})$ & Root length $(\mathrm{mean} \pm \mathrm{SD})$ \\
\hline Control 1 & - & - & $4.8 \pm 0.60^{\mathrm{e}}$ & $4.28 \pm 0.39^{\mathrm{e}}$ \\
Control 2 & - & - & $6.8 \pm 1.0^{\mathrm{e}}$ & $5.29 \pm 0.22^{\mathrm{d}}$ \\
RIM1 & 0.25 & - & $11.47 \pm 0.95^{\mathrm{cd}}$ & $5.57 \pm 0.08^{\mathrm{cd}}$ \\
RIM2 & 0.5 & - & $16.87 \pm 1.53^{\mathrm{ac}}$ & $6.55 \pm 0.20^{\mathrm{a}}$ \\
RIM3 & 1.0 & - & $11.20 \pm 1.11^{\mathrm{b}}$ & $5.87 \pm 0.29^{\mathrm{bc}}$ \\
RIM4 & - & 0.25 & $12.13 \pm 1.01^{\mathrm{bcd}}$ & $5.53 \pm 0.28^{\mathrm{cd}}$ \\
RIM5 & - & 0.5 & $14.27 \pm 0.76^{\mathrm{b}}$ & $6.23 \pm 0.08^{\mathrm{ab}}$ \\
RIM6 & - & 1.0 & $10.60 \pm 0.60^{\mathrm{d}}$ & $5.31 \pm 0.06^{\mathrm{d}}$ \\
\hline
\end{tabular}

Control 1 (full strength MS media) and Control 2 (half strength MS media). $\mathrm{N}=3$ with minimum of 5 explants per treatment. Value in column represents mean \pm Standard deviation. Mean with same letter with in column are not significantly different $(\mathrm{P} \leq 0.05)$.

Table 3. List of Primers used and genetic homogeneity analysis of regenerated plantlets:

\begin{tabular}{cccccc}
\hline S. No. & Primer ID & Primer Sequence & Tm $\left({ }^{\circ} \mathrm{C}\right)$ & No. of amplified bands & Amplified product range (KB) \\
\hline 1 & SCoT_1 & CAACAATGGCTACCACCA & 42 & 3 & $0.9-1.5$ \\
2 & SCoT_2 & CAACAATGGCTACCACCC & 42 & 4 & $0.8-2.0$ \\
3 & SCoT_3 & CAACAATGGCTACCACCG & 42 & 4 & $1.0-2.5$ \\
4 & SCoT_4 & CAACAATGGCTACCACCT & 42 & 6 & $1.0-2.5$ \\
5 & SCoT_5 & ACGACATGGCGACCGCGA & 45 & 6 & $0.6-2.2$ \\
6 & SCoT_6 & ACCATGGCTACCACCGCC & 45 & 3 & $0.9-2.0$ \\
7 & SCoT_7 & CATGGCTACCACCGGCCC & 45 & 5 & $0.6-2.4$ \\
8 & SCoT_8 & GCAACAATGGCTACCACC & 45 & 2 & $1.1-1.3$ \\
9 & ISSR_1 & TCTCTCTCTCTCTCTCRT & 45 & 4 & $0.9-2.0$ \\
10 & ISSR_2 & TCTCTCTCTCTCTCTCRG & 45 & 5 & $0.4-2.4$ \\
11 & ISSR_3 & TGTGTGTGTGTGTGTGRA & 45 & 3 & $1.0-1.6$ \\
12 & ISSR_4 & CACACACACACACACARC & 50 & 4 & $0.4-2.0$
\end{tabular}




\subsection{Statistical Analysis}

All data presented were the mean values of at least 3 independent experiments with 3 replicates each. Analysis of variance (One way ANOVA) at $\mathrm{P} \leq 0.05$ in SPSS version 17 (SPSS Inc., Chicago, USA), followed by Duncan's post hoc test to calculate the mean significant difference using SPSS software.

\section{Results}

\subsection{Direct Regeneration from Nodal Segment of Flower Stalk}

The flower stalk (Figure 1(a)) which contains 6 - 8 nodal regions was cut down into small pieces and used as an explant. Explant which did not have nodal region did not respond to shooting media (Figure 1(b)). Few explants were grown in MS medium without any growth regulator produced one shoot after 4 weeks (Figure 1(c)). The explants inoculated on SIM2 and SIM6 media showed small greenish callus like structure at nodal region after 13 - 15 days of culture initiation, which further turned into multiple shoot clumps (Figure 1(d)). During subculture cycle these multiple shoot clumps were trimmed off from the flower stalk segment and divided into 4 - 5 sections for proper growth and multiplication of shoots (Figure 1(e) and Figure 1(f)). These shoots clumps were allowed to grow for 8 - 10 weeks on shoot induction media under continuous subculturing (Figure 1(g)). The number of shoots per explant on different media was calculated after 6 weeks and is tabulated in Table 1. The SIM2 media showed best shoot regeneration of $15.27 \pm 1.14$ per explant as compared to SIM6 where $12.60 \pm 1.20$ were regenerated. Rest of the shooting media showed decrease in shoot number with increase or decrease of cytokinin concentration.

\subsection{In Vitro Rooting and Acclimatization}

Individual shoots separated from multiple shoots clump were separated carefully and kept on rooting medium (Figure 2(a)). After 6 weeks, roots formed from a single separated shoot of inoculation on different media were counted and is shown in Table 2. MS full strength media showed $4.8 \pm 0.60$ roots per shoot with a root length of $4.28 \pm 0.39$, whereas few separated plants did not respond to the media. However, half MS showed better response $6.8 \pm 1.0$ roots per explant with the root length of $5.29 \pm 0.22$. Addition of auxins such as IAA and NAA in MS medium enhanced the roots formation. RIM2 and RIM5 were found to be more efficient in inducing roots, producing $16.87 \pm 1.53$ and $12.13 \pm 1.51$ with a root length of $6.55 \pm 0.20$ and $5.53 \pm 0.28$, respectively (Table 2). Rooted plants were taken out from tube and washed with water to remove excess of agar without damaging roots (Figure 2(b)). Plantlets were then transferred into pots having soilrite and covered with transparent poly bags for 2 weeks acclimatization (Figure 2(c)). All acclimatized plants did not show any morphological variations and tubers were formed within 4 - 5 months (Figure 2(d) and Figure 2(e)). 

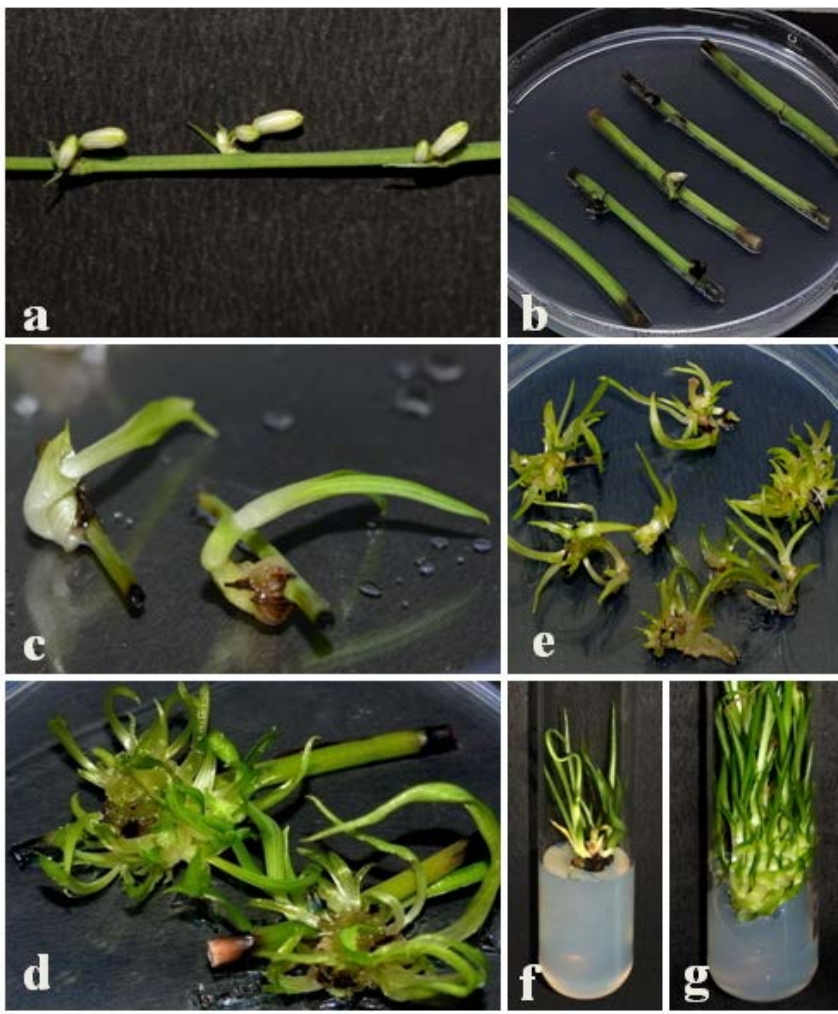

Figure 1. (a) Flower stalk (explant) of $C$. borivilianum; (b) Inoculation on SIM2 media after sterilization; (c) Shoot proliferation on hormone free media (MS only); and (d) on SIM2 media; (e) Shoot regeneration after excising proliferating meristematic region into smaller segments on SIM2 media; (f) Shoot growth from one segment (after excising) of meristematic region on SIM2 media; (g) Multiple Shoot growth on SIM2 media.

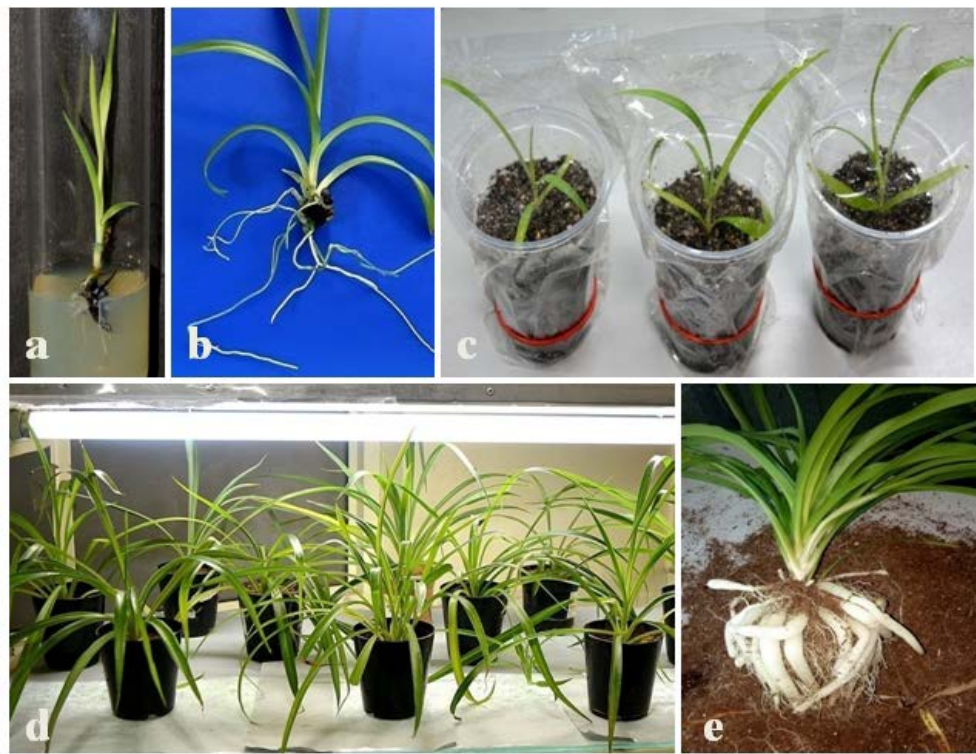

Figure 2. (a) Inoculation of individually separated shoot on root induction media; (b) Fully grown plantlet showing healthy shoot and roots after 6 weeks of inoculation on rooting media; (c) Acclimatized plantlets with no morphological changes after3weeks of hardening; (d) Hardened plants after 4 months on soilrite; (e) Fully grown healthy plant after 5 months. 


\subsection{SCoT and ISSR Analysis}

Genetic homogeneity of 18 randomly selected plantlets was done using SCoT and ISSR primers. Each SCoT and ISSR primer showed the amplified bands within the range of 0.4 to $2.5 \mathrm{~KB}$ (Table 3 ). Eight SCoT primers generated total 33 reproducible PCR bands with an average of 4.08 bands per primer. In case of ISSR, a total of 16 bands were amplified using 4 primers with an average of 4 bands per primer. All the in vitro grown plantlets showed same banding pattern as identical to the mother plant (Figure 3 ).

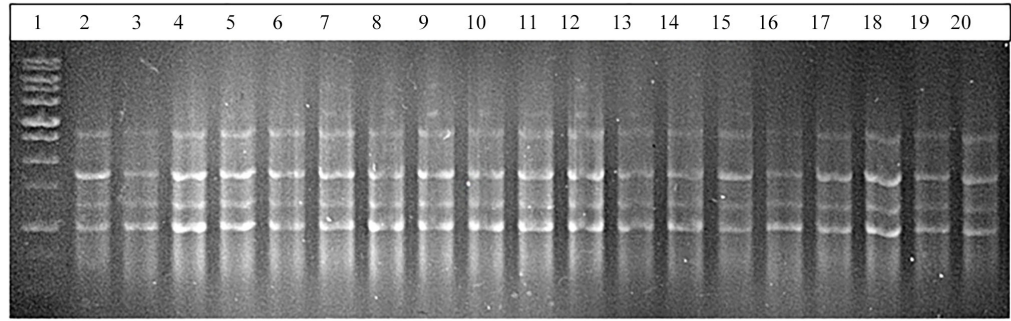

(a) $\mathrm{SCoT} 3$

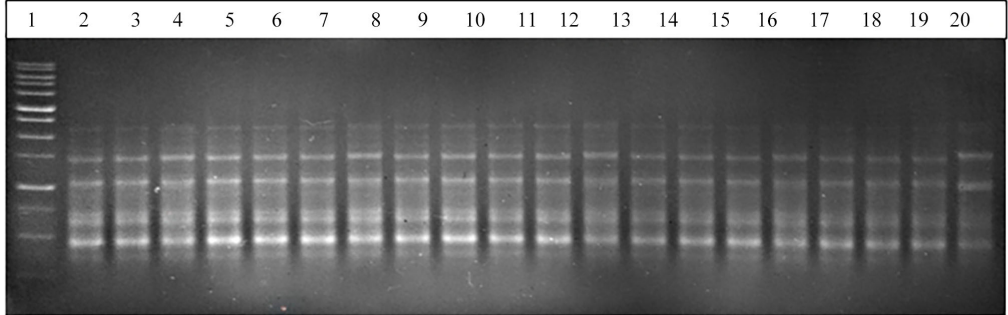

(b) $\mathrm{SCoT} 5$

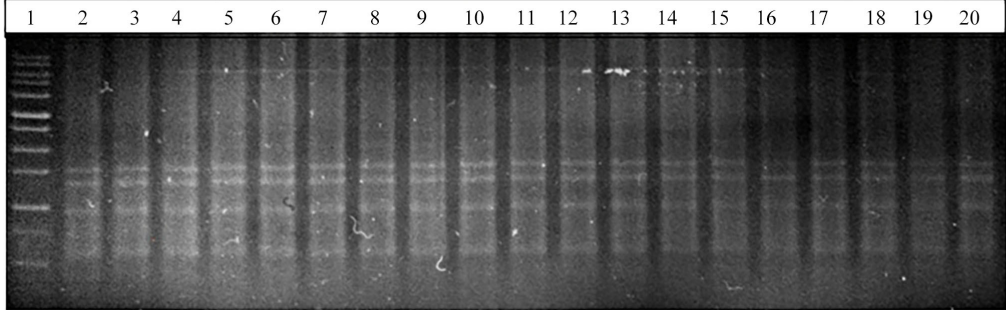

(c) ISSR

Figure 3. Showing DNA profiles of mother plant and 18 tissue culture raised plantlets of C. borivilianum; SCoT_3 (3a), SCoT_5 (3b), ISSR_1 (3c). Lane 1: 1 KB DNA ladder; Lane 2: DNA banding pattern of mother plant; L3 - L120 showing DNA banding pattern of direct regenerated plantlets.

\section{Discussion}

Ease of explant availability, less contamination frequency and genetic stability in regenerants are the most important factors which were considered during explant selection. In previous reports, mostly shoot buds, and stem discs have been used as initial explants [26] [27]. The major limitations of these explants are sacrificing whole plant and higher contamination probability. In some other studies, immature inflorescence was used, however its availability is limited as compared to flower stalk which remains with the plant even after perishing of the inflorescence [8] [15]. Moreover, flower stalk is less delicate and easy to handle as compare to immature inflorescence and axillary buds during in vitro culturing. The plant hormones and their optimum concentration play a key role in decid- 
ing the fate of plant tissues and also, maintaining the genetic fidelity. In earlier studies of direct shoot regeneration, young shoot buds [26], stem discs [27], immature inflorescence and floral buds [8] [15] were used as explant for micropropagation in C.borivilianum. For shoot regeneration, young shoot buds [26] were inoculated onto MS medium supplemented BAP and KIN. In another study, immature floral buds attached with inflorescence axis were used as explant for direct regeneration. MS medium supplemented with $2 \mathrm{mg} / \mathrm{l}$ kinetin and $0.1 \mathrm{mg} / \mathrm{l}$ 2, 4-D showed best response for multiple shoot induction [15].

In earlier study, Samantray et al. (2009) used middle segment located just behind the apex of immature inflorescence for shoot regeneration where BAP (3 $\mathrm{mg} / \mathrm{L}$ ) in combination with $\mathrm{AdSO}_{4}$ and NAA produced 7.4 shoots per explant and no response was observed using KIN supplemented media [8]. In our study, using single nodal segment a maximum no. of $15.27 \pm 1.14$ and $12.60 \pm 1.20$ shoots were regenerated on SIM2 and SIM6 supplemented media, respectively. The no. of shoots was quite higher on both media as compare to earlier reports [8]. The protocol established by Sharma and Mohan (2006) using immature floral buds took approximately 50 weeks to field transfer of in vitro grown plants which is quite a long time as compare to our established protocol where $24-25$ weeks were taken to produce hardened plants. MS media having $0.5-1 \mathrm{mg} / \mathrm{L}$ IAA/NAA/IBA showed better rooting frequency as compare to other growth regulators, which is in accordance with the previous reports of $C$. borivilianum [15] [26]. In our study, NAA ( $0.5 \mathrm{mg} / \mathrm{L})$ showed best rooting response over IAA. Number of roots started to decrease with the increase in concentration.

To check the genetic fidelity of tissue culture raised plants various molecular markers are available. Nowadays, SCoT and ISSR markers are gaining much attention due to their better resolvability over other markers [14] [33] [34]. Moreover, use of more than one marker i.e., ISSR and SCoT is advantageous to justify the results more evidently. The SCoT markers have start codon (ATG) in their sequence [35] whereas, ISSR marker are based on the non-coding regions of the DNA [33]. In recent studies, SCoT and ISSR markers have been frequently used for assessing the genetic stability of several medicinal plants such as Morus alba, Pittosporum eriocarpum, Cleome gynandra and Albizia julibrissin [14] [23] [33] [35] where the results were quite promising as compare to the other markers. A previous study showed polymorphic information content (PIC), of SCoT was more informative with better distinction power than the other markers. SCoT and ISSR markers dendrograms also showed a close relationship in bamboo genotypes [36]. In another study where SCoT, ISSR and directly amplified minisatellite DNA (DAMD) markers were studied together for fingerprinting of chickpea genotypes showed that SCoT and ISSR markers were quite informative as compare to other markers for the genetic assessment [37]. In case of C. borivilianum, there are very few reports on genetic assessment of in vitro grown plants. Arora et al. (2006) reported that long-term embryogenic cultures of $C$. borivilianum showed variation using RAPD markers [28]. In earlier study of direct rege- 
neration in $C$. borivilianum using stem disc as an explant, Samantray and Maity, (2010) using RAPD markers showed monomorphism with the mother plant [38]. In our study using SCoT and ISSR markers where 18 randomly selected in vitro raised plants using flower stalk internodes showed similarity to the mother plant, hence maintaining the genetic homogeneity (Table 3 ).

The developed protocol using flower stalk internodes significantly reduced the risk of somaclonal variations as compare to other regeneration methods. This is the first report assessing genetic stability of regenerated plantlets using SCoT and ISSR markers in C. borivilianum. Thus, this method could be used for micro propagation for its efficient mass multiplication and conservation using flower stalk to maintain genetic stability of the $C$. borivilianum.

\section{Conclusion}

C. borivilianum is the endangered medicinal plant, whose mass propagation is in demand for agricultural and commercial purposes. We have optimized media for direct regeneration using flower stalk of the plant. For the first time, in vitro propagation through direct regeneration using nodal segments and their genetic fidelity analysis has been done successfully. The used markers and its amplified band pattern might be helpful to screen large populations to detect genetic variation in $C$. borivilianum.

\section{Acknowledgements}

NK is thankful to University grants commission (U.G.C.), New Delhi for providing the fellowship under BSR scheme. Authors are thankful to Department of Biotechnology for providing the necessary facilities to conduct experiments.

\section{Conflicts of Interest}

The authors declare no conflicts of interest regarding the publication of this paper.

\section{References}

[1] Tandon, M. and Shukla, Y.N. (1992) Sapogenins from Asparagus adscendens and Chlorophytum arundinaceum. Journal of the Indian Chemical Society, 69, 893.

[2] Khanam, Z., Singh, O., Singh, R. and Bhat, I.U.H. (2013) Safed Musli (Chlorophytum borivilianum): A Review of Its Botany, Ethnopharmacology and Phytochemistry. Journal of Ethnopharmacology, 150, 421-441. https://doi.org/10.1016/j.jep.2013.08.064

[3] Kaushik, N. (2005) Saponins of Chlorophytum Species. Phytochemistry Reviews, 4, 191-196. https://doi.org/10.1007/s11101-005-2607-5

[4] Lavania, U.C., Basu, S., Srivastava, S., Mukai, Y. and Lavania, S. (2005) In Situ Chromosomal Localization of rDNA Sites in "Safed Musli" Chlorophytum Ker-Gawl and Their Physical Measurement by Fiber FISH. Journal of Heredity, 96, 155-160. https://doi.org/10.1093/jhered/esi018

[5] Bordia, P.C., Joshi, A. and Simlot, M.M. (1995) Safed Musli. In: Chadha, K.L., Gup- 
ta, R., Eds., Advances in Horticulture (Medicinal and Aromatic Pants), Vol. 11, Malhotra Publication House, New Delhi, 429-451.

[6] Rizvi, M.Z., Kukreja, A.K. and Khanuja, S.P.S. (2007) In Vitro Culture of Chlorophytum borivilianum Sant. et Fernand. in Liquid Culture Medium as a Cost-Effective Measure. Current Science, 92, 87-90.

[7] Rizvi, M.Z. and Kukreja, A.K. (2010) In Vitro Propagation of an Endangered Medicinal Herb Chlorophytum borivilianum Sant. et Fernand. through Somatic Embryogenesis. Physiology and Molecular Biology of Plants. An International Journal of Functional Plant Biology, 16, 249-257. https://doi.org/10.1007/s12298-010-0026-6

[8] Samantaray, S., Kumar, S.V. and Maiti, S. (2009) Direct Shoot Regeneration from Immature Inflorescence Cultures of Chlorophytum arundinaceum and Chlorophytum borivilianum. Biologia, 64, 305-309. https://doi.org/10.2478/s11756-009-0039-1

[9] Apollonio, G., Scaramuzzi, F. and D'emerico, S. (1990) Observations on the Stability of Ploidy and on the Behaviour of Variegation Transmission in the Cultures and Related Subcultures of Chlorophytum comosum Bak. var. Foliismedio Variegatis Hort. Comptes rendus des séances de la Société de biologie et de ses filiales, 184, 240-250.

[10] Purohit, S.D., Dave, A. and Kukda, G. (1994) Micropropagation of Safed Musli (Chlorophytum borivilianum), a Rare Indian Medicinal Herb. Plant Cell, Tissue and Organ Culture, 39, 93-96. https://doi.org/10.1007/BF00037596

[11] Cui, J., Liu, J., Chen, J. and Henny, R.J. (2011) Regeneration of Chlorophytum amaniense "Fire Flash" through Indirect Shoot Organogenesis. HortScience, 46, 466-469. https://doi.org/10.21273/HORTSCI.46.3.466

[12] Nakasha, J., Sinniah, U.R., Kemat, N. and Swamy, M. (2016) Induction, Subculture Cycle, and Regeneration of Callus in Safed Musli (Chlorophytum borivilianum) Using Different Types of Phytohormones. Pharmacognosy Magazine, 12, 460-464. https://doi.org/10.4103/0973-1296.191457

[13] Arora, D.K., Sun, S.S., Ramawat, K.G. and Merillon, J. (1999) Factors Affecting Somatic Embryogenesis in Long Term Callus Cultures of "Safed Musli" (Chlorophytum borivilianum), an Endangered Wonder Herb. Indian Journal of Experimental Biology, 37, 75-82.

[14] Rohela, G.K., Jogam, P., Mohammad, M., et al. (2020) Indirect Regeneration and Genetic Fidelity Analysis of Acclimated Plantlets through SCoT and ISSR Markers in Morus alba L. cv. Chinese White. Biotechnol. Reports.

[15] Sharma, U. and Mohan, J.S.S. (2006) In Vitro Clonal Propagation of Chlorophytum borivilianum Sant. et Fernand., a Rare Medicinal Herb from Immature Floral Buds Along with Inflorescence Axis. Indian Journal of Experimental Biology, 44, 177-182.

[16] Bairu, M.W., Aremu, A.O. and van Staden, J. (2011) Somaclonal Variation in Plants: Causes and Detection Methods. Plant Growth Regulation, 63, 147-173. https://doi.org/10.1007/s10725-010-9554-x

[17] Duncan, R.R. (1996) Tissue Culture-Induced Variation and Crop Improvement. Advances in Agronomy, 58, 201-240. https://doi.org/10.1016/S0065-2113(08)60256-4

[18] Krishna, H., Alizadeh, M. and Singh, D. (2016) Somaclonal Variations and Their Applications in Horticultural Crops Improvement. 3 Biotech, 6, 1-18. https://doi.org/10.1007/s13205-016-0389-7

[19] Ostray, M.E., Hackett, W., Michler, C., Serres, R. and McCown, B. (1994) Influence of Regeneration Method and Tissue Culture on the Frequency of Somatic Variation 
in Populus to Infection by Septoriamusiva. Plant Science, 97, 209-215. https://doi.org/10.1016/0168-9452(94)90058-2

[20] Rani, V. and Raina, S.N. (2000) Genetic Fidelity of Organized Meristem Derived Micropropagated Plants: A Critical Reappraisal. In Vitro Cellular \& Developmental Biology_Plant, 36, 310-330. https://doi.org/10.1007/s11627-000-0059-6

[21] Bindiya, K. and Kanwar, K. (2003) Random Amplified Polymorphic DNA (RAPDS) Markers for Genetic Analysis in Micropropagated Plants of Robinia pseudoacacia L. Euphytica, 132, 41-47. https://doi.org/10.1023/A:1024623517374

[22] Sucher, N.J. and Carles, M. (2008) Genome-Based Approaches to the Authentication of Medicinal Plants. Planta Medica, 74, 603-623. https://doi.org/10.1055/s-2008-1074517

[23] Rathore, N.S., Rai, M.K., Phulwaria, M., Rathore, N. and Shekhawat, N.S. (2014) Genetic Stability in Micropropagated Cleome gynandra Revealed by SCoT Analysis. Acta Physiologiae Plantarum, 36, 555-559. https://doi.org/10.1007/s11738-013-1429-0

[24] Bhattacharyya, P., Kumaria, S., Kumar, S. and Tandon, P. (2013) Start Codon Targeted (SCoT) Marker Reveals Genetic Diversity of Dendrobium nobile Lindl., an Endangered Medicinal Orchid Species. Gene, 52, 21-26. https://doi.org/10.1016/j.gene.2013.07.096

[25] Sadhu, S.K., Jogam, P., Thampu, R.K., Abbagani, S., Penna, S. and Peddaboina, V. (2020) High Efficiency Plant Regeneration and Genetic Fidelity of Regenerants by SCoT and ISSR Markers in Chickpea (Cicer arietinum L.). Plant Cell, Tissue and Organ Culture, 141, 465-477. https://doi.org/10.1007/s11240-020-01804-7

[26] Sen, M.K., Nasrin, S., Rahman, S. and Jamal, A.H.M. (2014) In Vitro Callus Induction and Plantlet Regeneration of Achyranthes aspera L., a High Value Medicinal Plant. Asian Pacific Journal of Tropical Biomedicine, 4, 40-46. https://doi.org/10.1016/S2221-1691(14)60206-9

[27] Kemat, N., Kadir, M.A., Ashikin, N. and Abdullah, P. (2010) Rapid Multiplication of Safed Musli (Chlorophytum borivilianum) through Shoot Proliferation. African Journal of Biotechnology, 9, 4595-4600.

[28] Mathur, A., Mathur, A.K., Verma, P., Yadav, S., Lal Gupta, M. and Darokar, M.P. (2008) Biological Hardening and Genetic Fidelity Testing of Micro-Cloned Progeny of Chlorophytum borivilianum Sant. et Fernand. African Journal of Biotechnology, 7, 1046-1053.

[29] Arora, D.K., Sarabjeet, S.S. and Ramawat, K.G. (2006) Assessments of Variability in the Regenerants from Long Term Culture of Safed Musli (Chlorophytum borivilianum). Indian Journal of Biotechnology, 5, 527-534.

[30] Priyadharshini, S., Kannan, N., Manokari, M. and Shekhawat, S.M. (2020) In Vitro Regeneration Using Twin Scales for Restoration of Critically Endangered Aquatic Plant Crinum malabaricum Lekhak \& Yadav: A Promising Source of Galanthamine. Plant Cell, Tissue and Organ Culture, 141, 593-604. https://doi.org/10.1007/s11240-020-01818-1

[31] Jogam, P., Sandhya, D., Shekhawat, M.S., Alok, A., Abbagani, M.M.S. and Allini, V.R. (2020) Genetic Stability Analysis Using DNA Barcoding and Molecular Markers and Foliar Micro-Morphological Analysis of in Vitro Regenerated and in Vivo Grown Plants of Artemisia vulgaris L. Industrial Crops and Products, 151, Article ID: 112476. https://doi.org/10.1016/j.indcrop.2020.112476

[32] Thakur, J., Dwivedi, M.D., Sourabh, P., et al. (2016) Genetic Homogeneity Revealed Using SCoT, ISSR and RAPD Markers in Micropropagated Pittosporum eriocarpum 
Royle-An Endemic and Endangered Medicinal Plant. PLoS ONE, 11, e0159050. https://doi.org/10.1371/journal.pone.0159050

[33] Murashige, T. and Skoog, F. (1962) A Revised Medium for Rapid Growth and Bioassays with Tobacco Tissue Cultures. Physiologia Plantarum, 15, 473-497. https://doi.org/10.1111/j.1399-3054.1962.tb08052.x

[34] Gorji, A.M., Poczai, P., Polgar, Z. and Taller, J. (2011) Efficiency of Arbitrarily Amplified Dominant Markers (SCOT, ISSR and RAPD) for Diagnostic Fingerprinting in Tetraploid Potato. American Journal of Potato Research, 88, 226-237. https://doi.org/10.1007/s12230-011-9187-2

[35] Collard, B.C.Y. and Mackill, D.J. (2009) Start Codon Targeted (SCoT) Polymorphism: A Simple, Novel DNA Marker Technique for Generating Gene-Targeted Markers in Plants. Plant Molecular Biology Reporter, 27, 86-93.

https://doi.org/10.1007/s11105-008-0060-5

[36] Rahmani, M., Pijut, P.M., Shabanian, N. and Nasri, M. (2015) Genetic Fidelity Assessment of in Vitro-Regenerated Plants of Albizia julibrissin Using SCoT and IRAP Fingerprinting. In Vitro Cellular \& Developmental Biology_Plant, 51, 407-419. https://doi.org/10.1007/s11627-015-9692-y

[37] Thoungamba, A., Leimapokpam, T., Nandeibam, A., Goutam, M., Sonia, P., Koijam, A.S., Potshangbam, A.M., Rahaman, H. and Nongdam, P. (2020) Efficiency of RAPD, ISSR, iPBS, SCoT and Phytochemical Markers in the Genetic Relationship Study of Five Native and Economical Important Bamboos of North-East India. Phytochemistry, 174, Article ID: 112330. https://doi.org/10.1016/j.phytochem.2020.112330

[38] Pakseresht, F., Talebi, R. and Karami, E. (2013) Comparative Assessment of ISSR, DAMD and SCoT Markers for Evaluation of Genetic Diversity and Conservation of Landrace Chickpea (Cicer arietinum L.) Genotypes Collected from North-West of Iran. Physiology and Molecular Biology of Plants, 19, 563-574.

https://doi.org/10.1007/s12298-013-0181-7 